\title{
2001-2002 Canadian Association of Emergency Physicians Research Grant Competition
}

\author{
Eric Grafstein, MD;* Brian H. Rowe, MD; $\dagger$ \\ for the CAEP Research Committee and CAEP Research Consortium
}

$\mathrm{T}$ he continued success of the Canadian Association of Emergency Physicians (CAEP) Research Grant Competition is an example of supplemental research funding developed by CAEP that is only made available to researchers in emergency medicine. Over the years, this competition has allowed CAEP researchers and their collaborators to compete for grants (up to $\$ 5,000$ ) to conduct emergency medicine research. Many of the previously funded projects have been presented at CAEP annual scientific conferences and other national and international meetings.

This competition is made possible by Hoffmann-La Roche Limited (Roche), who provide generous unrestricted educational grants to sponsor the event on an annual basis. Hoffmann-La Roche has been a major contributor and supporter of emergency medicine research in Canada and they are the sole contributor to this research collaboration.

This year, the CAEP Grant Competition received 18 excellent submissions prior to the Sept. 4th deadline, and awarded a total of $\$ 30000$ to fund 7 projects. The growing number of grant submissions demonstrates both increasing activity in Canadian emergency medicine research, and the need to seek additional sponsorship for this important competition. The Research Committee regrets that it could not fund all of the applicants!

Each grant was reviewed independently by 2 researchers, and the top 7 applicants were awarded funding. Six accepted. The following list outlines the name and affiliation of the principal investigator, the title of the project and the funding allocated by CAEP.

1. Jeff Perry, MD. Division of Emergency Medicine, University of Ottawa, Ottawa, Ont. Emergency department decision rule for subarachnoid hemorrhage. $\$ 5,000$. [Note: Dr. Perry also received funding for this project from the Ontario Physicians' Incorporate Foundation and graciously asked that the CAEP funding be awarded to another applicant.]

2. Chris Denny, MD. Division of Emergency Medicine, University of Toronto, Toronto, Ont. Socioeconomic status and survival in prehospital cardiac arrest. $\$ 4,400$.

3. Michel Roy, MD. Division of Emergency Medicine, Department of Pediatrics, Hôpital Ste-
Justine, Montreal, Que. Dexamethasone for the treatment of sore throat in acute infectious mononucleosis: a double blind, randomized, placebo control clinical trial. $\$ 5,000$.

4. Devon Harris, MD. Department of Emergency Medicine, St. Paul's Hospital, Vancouver, BC. Emergency physicians' attitudes towards a clinical prediction rule for the identification and early management of transient ischemic attacks. $\$ 5,000$.

5. Sarah Gray, MD. Division of Emergency Medicine, University of Toronto, Toronto, Ont. What is the publication record of CAEP resident research presenters? $\$ 5,000$.

6. Ran D. Goldman, MD. Division of Pediatric Emergency Medicine and General Pediatrics, The Hospital for Sick Children, University of Toronto, Toronto, Ont. Children leaving a pediatric emergency department without being seen by a pediatrician: Why don't they stay and where do they go? $\$ 4,940$.

7. Benoit Bailey, MD. Division of Emergency Medicine, Department of Pediatrics, Hôpital Ste.

*University of British Columbia, Vancouver, BC; +University of Alberta, Edmonton, Alta. 
Justine, Montreal, Que. Emergency physicians' use of sleep aids before or after night shift. $\$ 5,000$.

In accepting the research award, certain requirements were made of the primary investigators. First, all grants were provided to recipients as peer-reviewed unrestricted educational grants from CAEP; in other words, all budgets must be expended on grant items and not on institutional overhead. There is an expectation that grant recipients will provide CAEP, through the Research Committee, with a final report and a full financial statement regarding the allocation of resources at the conclusion of the study. As well, a completed manuscript is required prior to reapplying for another CAEP grant. Finally, all presentations and publications of the findings are required to acknowledge the CAEP Research Grant contributions to their research.

On behalf of the Research Committee, the CAEP Board and Hoffmann-La Roche, we would like to thank all CAEP members who took the time to apply for these grants. We would like to congratulate the grant recipients for their success in this year's competition. We wish them success in their research endeavours and hope to see the results presented at a future CAEP meeting.

Acknowledgements: The CAEP Research Committee acknowledges the support of Hoffmann-La Roche Limited in making these grants available. In particular, we recognize Dr. Lorraine Paul (Associate Director, Cardiovascular) from of Hoffmann-La Roche, for her interest and commitment to this project. We personally thank Mrs. Sue Norrington for her efforts in coordinating this competition and Dr. Douglas Sinclair for his efforts in promoting this collaboration. We thank Dr. Andrew Worster, Damon Mayes and Carol Spooner for their assistance with grant reviews.

Correspondence to: Dr. Eric Grafstein, egraf stein@ providencehealth.bc.ca; or Dr. Brian H. Rowe, Brian.Rowe@ualberta.ca

\section{NOTICE OF CHANGE OF ADDRESS AVIS DE CHANGEMENT D'ADRESSE}

To ensure that you continue to receive the Canadian Journal of Emergency Medicine (CJEM) without interruption, please fill in and mail this form before you move.

Avant de déménager, assurez-vous de recevoir sans interruption le Journal canadien de la médecine d'urgence (JCMU) en complétant et en expédiant le formulaire suivant.

Please print / En lettres moulées, svp

Name / Nom .

Old address / Ancienne adresse

New address / Nouvelle adresse.

Date effective / Date en vigueur.

Subscribers please mail to: Canadian Association of Emergency Physicians, 104-1785 Alta Vista Dr., Ottawa ON K1G 3 Y6.

Abonnés, veuillez expédier au : Association canadienne des médecins d'urgence, 104-1785, prom. Alta Vista, Ottawa ON K1G 3 Y6. 